\title{
Assessment of Economic Impact Studies: The Cases of BMW and Mercedes-Benz
}

\author{
John E. Connaughton and Ronald A. Madsen*
}

\begin{abstract}
In 1992, the state of South Carolina offered an incentive package in excess of $\$ 120$ million for the possible location of a BMW auto assembly plant. As part of the location effort, the state of South Carolina sponsored an impact study that appeared to be very optimistic. This paper evaluates this very optimistic impact study. The results presented in this paper fail to support the assumption made in the South Carolina impact study that 21 net new supplier chain firms would accompany a new BMW plant opening. Our findings suggest that the impact studies overestimated the total impact on the state economy.
\end{abstract}

\section{INTRODUCTION}

Competition among regions for economic development has reached an unprecedented level of intensity in recent years. Increasingly, cities, regions, and states are providing large economic incentives, derived from taxpayer revenues, to attract new and expanding industries. As this competition escalates, the need to accurately measure the economic benefits to justify taxpayer incentives increases. In the early 1990s, BMW and Mercedes-Benz encouraged states to bid for the location of two new U.S. assembly plants. The incentive packages provided by the winners, South Carolina and Alabama, were estimated to be in excess of 130 million and 300 million taxpayer dollars, respectively.

In 1992, the state of South Carolina produced a study (South Carolina State Development Board 1992) that estimated the economic impact of the proposed BMW manufacturing plant on the South Carolina economy. The BMW study estimates were based on 1,900 direct (on-site) jobs that were to be provided by BMW. In 1993, the state of Alabama commissioned a study (Holmes and McCallum 1993) to estimate the economic impact of the proposed Mercedes-Benz plant on the Alabama economy. The Mercedes-Benz study estimates were based on 1,500 direct (on-site) jobs that were to be provided by Mercedes-Benz.

Based on the results of these two studies, it appears that South Carolina was willing to pay $\$ 68,421$ per direct job and Alabama was willing to pay $\$ 300,000$ per direct job. Did these decisions make good public policy sense? A number of different impact studies were used by the states involved in the bidding war to justify their incentive packages.

The purpose of this paper is to evaluate the optimistic impact studies completed for South Carolina and Alabama and to determine, ex post, how accurate these state-sponsored studies were. Both studies appear to commit a common error of double counting indirect jobs. Based on information about new supplier chain firms resulting from new Toyota and Saturn plants, the South Carolina and 
Alabama studies made assumptions about the number and size of new supplier chain industries that would locate in the immediate area to support the new plants. Both studies then included the estimates of these new supplier chain firms as direct impacts.

A question arises as to why these states would make assumptions that might cause their impact studies to overestimate the impact that these new plants would have on the state's economy. Jenn and Nourzad (1996) found evidence that the economic development communities in many states are essentially in an "arms race" when it comes to major relocation activities. They suggest that, "the escalating level of incentives may be eroding the marginal benefit associated with offering such incentives" (Jenn and Nourzad 1996, p. 12). Providing impact studies that estimate large benefits for the local economy might put back into balance, and therefore justify, the level of incentive necessary to be competitive for some major relocation activities.

Now that time has passed, it is possible to look at firm and employment data in the typical supplier chain industries and to determine if the methodological approach used by both studies has proven to be appropriate. The important methodological question is how do you adjust for the indirect economic impact of a major new firm in an area that previously did not have a significant presence in the industry category? This paper addresses that issue and compares the firm and employment growth results to the predicted impacts.

\section{REVIEW OF ECONOMIC IMPACT STUDIES}

The three most important measures of the regional economic impact of an expanding or relocating plant are jobs, earnings, and dollar output. To assess accurately the economic impact, three important pieces of information should be available: direct jobs, direct earnings, and direct output. The term direct represents the on-site economic measures of the firm being evaluated. Typically new, expanding, or relocating firms only provide estimates of new jobs associated with the operation of the plant. These jobs represent direct jobs. Infrequently, new, expanding, or relocating firms provide information on direct earnings or direct output. This is usually not provided for competitive reasons; however, this lack of information limits the extent of the economic impact assessment.

Through its RIMS II program, the U.S. Department of Commerce, Bureau of Economic Analysis provides detailed employment, earnings, and output multipliers. These multipliers can be applied to the direct output or employment information to estimate the total impact of new, expanding, or relocating firms. With output information, RIMS II provides multipliers that can be used to estimate the aggregate total and indirect/induced output, earnings, and employment impacts at the state, county, or multicounty level. The difference between the total impact and the direct impact represents the indirect/induced impact of the new plant. It is important to note that the indirect and the induced effects are not specifically broken out by the RIMS II process. The indirect effect is the additional 
economic activity of the supplier chain, within the region, caused by the economic activity of the new, expanding, or relocating firm. The induced effect is the additional economic activity of all other unrelated firms and households, within the state, caused by the economic activity of the new, expanding, or relocating firm and the indirect effect.

The area of supplier chain linkages is important to the economic impact process. The RIMS II multiplier estimates the indirect impact based on the existing mix of industries (existing supplier chain) in the state or region. In the case where a new or relocating firm represents a new industry to the state, the multiplier will likely be quite low when compared to states that have a well-developed industry and a well-established supplier chain. With a small multiplier, the indirect/ induced impact will be less. It is possible that a supplier chain might develop over time, and an expanded supplier chain would increase the size of the multiplier in the future and increase the impact. However, whether this would occur, or the extent to which it would occur, is uncertain. Thus, supplier chain jobs should only be treated as new direct jobs to the extent that they are above the number of indirect supplier chain jobs already accounted for by the RIMS II multipliers.

Table 1 provides a summary of the job impacts estimated for BMW in South Carolina (South Carolina State Development Board 1992) and the MercedesBenz estimated job impacts in Alabama (Holmes and McCallum 1993). The estimated job impacts in South Carolina were made using RIMS II multipliers. The Alabama job impacts were estimated using IMPLAN multipliers, which are an alternative input-output model developed initially by the U.S. Forest Service and now maintained by the Minnesota IMPLAN Group, Inc.

TABLE 1

Mercedes Benz and BMW Impact Study Comparison

\begin{tabular}{|c|c|c|}
\hline Category & $\begin{array}{c}\text { BMW } \\
\text { South Carolina }\end{array}$ & $\begin{array}{c}\text { Mercedes-Benz } \\
\text { Alabama }\end{array}$ \\
\hline Direct on-site jobs & 1,900 & 1,500 \\
\hline Supplier firms & 21 & NA \\
\hline Direct supplier chain jobs & 2,793 & 2,875 \\
\hline Total direct jobs & 4,693 & 4,375 \\
\hline Indirect/Induced jobs & 5,444 & 5,200 \\
\hline Total jobs & 10,137 & 9,575 \\
\hline Multiplier & 2.16 & 2.19 \\
\hline
\end{tabular}

In the economic impact study for the BMW location in South Carolina, the RIMS II multipliers and the estimate of direct jobs were adjusted in an attempt to estimate the direct impact of an expanded supplier chain. In the South Carolina case, the BMW plant was expected to create 1,900 on-site jobs. Using the RIMS II methodology, only these 1,900 jobs would represent direct jobs. Indirect/induced jobs and total jobs would be estimated using the appropriate RIMS II multiplier for SIC code 371. However, the South Carolina study estimated that the location of the BMW plant in South Carolina would create an additional 21 automotive 
suppliers within the state and create 2,793 new supplier chain jobs. These jobs were classified as direct jobs. So the South Carolina study combined the 1,900 BMW jobs with the 2,793 estimated new supplier jobs for a total of 4,693 new direct jobs for South Carolina.

It is unlikely that all 2,793 of these supplier chain jobs are net, and therefore direct, additions to the South Carolina impact related to the 1,900 on-site BMW jobs. An aggregated multiplier of 2.16 was applied to the combined total of 4,693 direct jobs number (1,900 plus 2,793) producing 5,444 additional indirect/induced jobs and thus 10,137 total jobs. It is likely that this total jobs number overstated the job impact on the South Carolina economy.

There is no doubt that the supplier chain in the automotive industry within South Carolina would improve, and over time the multiplier might increase as a result of the BMW plant location. However, there is no guarantee as to the timing or size of the expanded supplier chain. The South Carolina study methodology may have provided misleading results because of the assumption that all the new supplier chain firms and jobs would be created contemporaneously with the new BMW plant.

Several studies support the concept that an expanded supplier chain in either South Carolina (for BMW) or Alabama (for Mercedes-Benz) is not a guarantee. Klier (1999) found that supplier plants tended to remain in the traditional upper Midwest so that they could take advantage of the "region's well-established highway transportation infrastructure" and "the ability to serve multiple customers from one location" (p. 304). In addition, Reid (1995) suggests that only "Japaneseowned manufacturing plants which use JIT (just-in-time) inventory control (systems) purchase a significantly higher proportion of their material inputs from inside their county" (p. 353).

A more conservative approach to identifying the possible supplier chain growth would likely provide a better estimate and understanding of the process involved as an industry expands within a state and a new supplier chain develops. One very simple way to do this would be to generate a two-stage estimate. First, use the standard RIMS II approach and classify the 1,900 BMW jobs as direct jobs and apply the RIMS II SIC code 371 multiplier to the direct jobs to calculate the indirect/induced and total job creation. This step would provide a baseline estimate of the job creation of the BMW plant, under current conditions, in the state of South Carolina. A second estimate based on the potential expansion of the supplier chain within the state could then be estimated. The most straightforward way to accomplish this would be to allow for a temporal adjustment in the original South Carolina RIMS II multiplier for SIC code 371. The temporal adjustment could be estimated based on multiplier changes observed in other states where an auto firm moved into a state with a small supplier chain network.

This is a more conservative approach, as it prevents the possible misunderstanding surrounding the likely timing of the supplier firm's impact. The separate measurement ensures that the supplier chain impact is viewed as potential 
and not as a given. It also avoids applying a multiplier to jobs already accounted for as the indirect/induced impact of on-site jobs. This approach would also overcome an additional methodological problem occurring in the South Carolina study of applying the SIC code 371 multiplier to both the new BMW jobs and the new supplier chain jobs created in a variety of industries.

References in the South Carolina impact study suggest that the supplier chain experiences of Tennessee's Saturn plant and/or Kentucky's Toyota plant were used to determine the expected number of new supplier chain firms anticipated to be attracted to the state. The study further assumed that each new supplier chain plant would be of average size for SIC 3714 and would thus employ 133 new supplier chain workers per plant. The assumption that these represent direct jobs to which standard RIMS II multipliers can be applied requires that all of these jobs be over and above the indirect jobs already reflected in the multiplier.

In a similar manner, the Alabama impact study, using IMPLAN multipliers instead of the RIMS II multipliers, projected that the 1,500 direct on-site jobs would be accompanied by an additional 2,875 supplier chain (direct) jobs in manufacturing. As indicated in Table 1, the combined direct jobs total 4,375 and an aggregate multiplier of 2.19 leads to a projection of 9,575 total jobs resulting from the plant location.

The projected job impacts in each study suggested effective multipliers versus the on-site job creation announced by BMW and Mercedes-Benz that approach or exceed the SIC 371 job multipliers in Michigan, Ohio, and other major car-producing states. In the BMW study, South Carolina was projected to gain 10,137 jobs versus the 1,900 on-site jobs. This suggests an effective multiplier versus the on-site jobs of $5.34(10,137$ divided by 1,900$)$. In the Alabama MercedesBenz study, the total jobs to on-site multiplier was effectively 6.38 (9,575 total jobs versus the 1,500 on-site jobs).

TABLE 2

1985 SIC Code 371 Employment Levels and Multipliers

\begin{tabular}{lccc}
\hline State & Employment & Number of Firms & RIMS II Employment Multipliers \\
\hline Michigan & 235,717 & 411 & 6.43 \\
Ohio & 101,869 & 253 & 6.01 \\
Indiana & 46,587 & 253 & 3.98 \\
California & 33,019 & 577 & 2.63 \\
Wisconsin & 28,993 & 90 & 5.13 \\
Illinois & 26,056 & 175 & 4.35 \\
New York & 25,699 & 169 & 2.56 \\
Pennsylvania & 23,712 & 151 & 3.56 \\
Tennessee & 20,320 & 96 & 3.90 \\
Georgia & 15,579 & 87 & 3.84 \\
\hline
\end{tabular}

Table 2 presents the SIC 371 employment levels, number of establishments, and RIMS II employment multipliers in Michigan, Ohio, and the other eight states that had the highest SIC 371 employment levels in 1985 (U.S. Department of Commerce 1992). The magnitudes of and variability in the multipliers are striking. Not 
surprisingly, Michigan had the highest SIC 371 employment, number of firms, and employment multiplier in 1985. What is somewhat surprising is that California, with the fourth highest employment, and New York, with the seventh highest employment, had the two smallest employment multipliers (2.63 and 2.56, respectively) among these 10 states. The effective on-site job multipliers in the South Carolina and Alabama impact studies (5.34 in South Carolina and 6.38 in Alabama) stand in stark contrast to the multipliers in most of these large automobileproducing states with well-developed supplier chain industries.

The methodology used in both studies under review produced effective on-site job multipliers that are more than double the SIC 371 employment multipliers for their respective states. Table 3 presents both of these multipliers for each of the studies and their respective states. In the Alabama study, the effective onsite multiplier of 6.38 is 2.04 times the SIC 371 RIMS II employment multiplier. The BMW study used an effective multiplier 2.09 times the SIC 371 RIMS II employment multiplier for South Carolina.

TABLE 3

Effective On-Site Jobs Multipliers versus SIC Code 371 RIMS II Jobs Multipliers

\begin{tabular}{lcc}
\hline State & $\begin{array}{c}\text { Impact Study Effective On-Site } \\
\text { Job Multipliers }\end{array}$ & $\begin{array}{c}\text { SIC Code 371 RIMS II } \\
\text { Jobs Multipliers }\end{array}$ \\
\hline Alabama & 6.38 & 3.13 \\
South Carolina & 5.34 & 2.55 \\
\hline
\end{tabular}

The argument that the siting of the BMW plant or Mercedes-Benz plant would induce supplier chain jobs beyond the respective state's existing multiplier number is entirely reasonable. That the multipliers should be doubled or more, and that they should approach or exceed the employment multipliers in Michigan, Ohio, and the other major automotive-producing states, does not seem plausible. The assumption that anticipated supplier chain jobs should all be treated as additional direct jobs leads to the exaggerated employment impacts.

TABLE 4

Comparisons of Existing Southeastern U.S. Auto Plants (1992)

\begin{tabular}{lrr}
\hline Category & \multicolumn{1}{c}{ Saturn } & \multicolumn{1}{c}{ Toyota } \\
\hline State & Tennessee & Kentucky \\
Number of cars & 196,126 & 220,000 \\
Number of suppliers (in-state) & 37 & 37 \\
Suppliers sales (in-state) & $\$ 273,000,000$ & $\$ 216,700,000$ \\
Number of employees & 5,800 & 4,350 \\
Per car in-state supplier content & $\$ 1,392$ & $\$ 985$ \\
Comments & Engine facility & Powertrain facility \\
\hline
\end{tabular}

Source: Information provided by Toyota (Lexington, Kentucky) and Saturn (Spring Hill, Tennessee).

The studies justified their estimates of supplier chain jobs based on the Saturn plant's impact on Tennessee and the Toyota plant's impact on Kentucky. Table 4 provides a comparison of these two plants in terms of number of cars produced in 1992, number of in-state suppliers, in-state supplier sales, number of on-site 
employees (excluding construction employment), and per car in-state supplier content. Both of these states already had significant supplier chain establishments, but the in-state per car supplier content reflected in Table 4 (\$1,392 for Saturn and $\$ 985$ for Toyota) suggests less-than-dramatic in-state supplier chain input and, hence, employment.

Certainly some of these supplier chain firms and jobs were already operating in the respective states prior to the siting announcements and start of operations. The expansion in jobs at these supplier chain firms then would be part of the indirect/induced employment gains associated with the on-site employment levels and production activity. Treating supplier chain jobs as direct jobs and then applying employment multipliers to these jobs suggests double counting of indirect jobs in particular and overstating of total job creation.

\section{ESTIMATING SUPPLIER CHAIN IMPACTS}

In an effort to get an accurate estimate of net supplier chain impacts and using the data provided in the U.S. Department of Commerce's 1992 Survey of Manufactures-Industry Series, 34 industries were identified as being important suppliers of SIC 3714. These industries are identified by SIC number in the Appendix.

Annual data on the number of firms and employment levels for each of these industries were collected for South Carolina for the years 1982-1997. This was the longest period of time available during which the data, provided in the U.S. Department of Commerce's County Business Patterns: South Carolina, were available for each of these SIC codes without changes in reporting procedures or changes in industry classifications. Regression analysis was used to determine the trend in firm growth during the 1982-1997 period. A dummy variable was used to determine whether there was a shift in either the intercept or the slope of the trend following the start of BMW plant operations in 1995. The following models were specified:

(1) Model 1: Firms $s_{t}=B_{o}+B_{1}$ Firms $_{t-1}+B_{2}$ Dummy $_{t}+e_{t}$ '

(2) Model 2: Firms $s_{t}=B_{o}+B_{1}$ Firms $_{t-1}+B_{2}$ Dummy $_{t}+B_{3}$ Trend $_{t}\left(\right.$ Dummy $\left._{t}\right)+e_{t}$ where

Firms $s_{\mathrm{t}}=$ The number of firms in $\mathrm{SIC}_{\mathrm{i}}$ in the state in a given year $\mathrm{t}$;

Dummy $_{t}=$ A dummy variable with a value of 0 in the years 1982-1994 and a value of 1 in the years 1995-1997; and

Trend $_{t}=$ A trend variable with a value of 1 in 1982, 2 in 1983, etc.

These models were estimated using the full sample of 34 industries over the 1982-1997 period. The results of these estimates for Model 1 and Model 2 are reported in Table 5 and Table 6, respectively. It would have been informative to estimate employment impacts along with the impacts on the number of firms, but because of nondisclosure requirements the data to estimate the employment impacts were so incomplete that employment impacts could not be estimated reliably. 
TABLE 5

Model 1 Regression Results for South Carolina

\begin{tabular}{lcccc}
\hline $\begin{array}{l}\text { Dependent Variable is Firms } \\
\text { Sample Size }=476\end{array}$ & \multicolumn{4}{l}{} \\
\hline Variable & Coefficient & Std. Error & t-Statistic & Prob. \\
\hline Constant & 0.488887 & 0.361046 & 1.354086 & 0.1764 \\
Firms ${ }_{\mathrm{t}-1}$ & 1.041331 & 0.01422 & 73.22818 & 0 \\
Dummy $_{\mathrm{t}}$ & 0.017611 & 0.723066 & 0.024356 & 0.9806 \\
$\mathrm{R}^{2}$ & 0.920317 & & Mean dependent var. & 12.48109 \\
Adjusted $^{2}$ & 0.91998 & S.D. dependent var. & 22.67216 \\
S.E. of regression & 6.413474 & F-statistic & 2731.493 \\
Sum squared resid. & 19455.74 & Prob(F-statistic) & 0 \\
\hline
\end{tabular}

TABLE 6

Model 2 Regression Results for South Carolina

Dependent Variable is Firms ${ }_{t}$

Sample Size $=476$

\begin{tabular}{|c|c|c|c|c|}
\hline Variable & Coefficient & Std. Error & t-Statistic & Prob. \\
\hline Constant & 0.48934 & 0.361434 & 1.353886 & 0.1764 \\
\hline Firms $_{t-1}$ & 1.041286 & 0.014239 & 73.13138 & 0 \\
\hline Dummy, & -1.549783 & 10.92426 & -0.141866 & 0.8872 \\
\hline Trend $_{t}\left(\right.$ Dummy $\left._{t}\right)$ & 0.111979 & 0.778744 & 0.143794 & 0.8857 \\
\hline $\mathrm{R}^{2}$ & 0.92032 & \multicolumn{2}{|c|}{ Mean dependent var. } & 12.48109 \\
\hline Adjusted $\mathrm{R}^{2}$ & 0.919814 & \multicolumn{2}{|c|}{ S.D. dependent var. } & 22.67216 \\
\hline S.E. of regression & 6.420124 & \multicolumn{2}{|c|}{ F-statistic } & 1817.232 \\
\hline Sum squared resid. & 19454.89 & \multicolumn{2}{|c|}{ Prob(F-statistic) } & 0 \\
\hline
\end{tabular}

The results in both Table 5 and Table 6 fail to show any impact that the BMW plant had on the number of firms in the 34 manufacturing supplier chain industries. The coefficient on the lagged dependent variable $\left(\right.$ Firms $\left._{t-1}\right)$ tests significant in both models. The estimated coefficient on this variable indicates that the number of firms per SIC industry increased at a rate of 1.041 times the previous year's number of firms (a 4.1 percent growth rate) per year over the 1982-1997 period. Since the coefficients on the Dummy ${ }_{t}$ variable in Model 1 and Model 2 are not significant, there is no evidence of a shift in the number of firms following the BMW plant opening in 1995.

Further, in Model 2 the coefficient on the interactive variable, Trend $_{t}\left(\right.$ Dummy $\left._{t}\right)$, does not test significant and thus there is no evidence of an increase in trend following the BMW plant opening in 1995. The 4.1 percent annual growth rate in the number of firms for predominantly auto industry supplier chain firms was established before the BMW plant was announced and the rate of growth did not change after the plant began operations. ${ }^{1}$

${ }^{1}$ The OLS models presented above were selected after a series of alternative specifications failed to produce better overall results, measured by adjusted $R^{2}$ and Mean Square Error. Among the alternative specifications was a limited dependent variable model estimated using LIMDEP and a Poisson regression with fixed effects. The results on the dummy for the presence of the auto plant never tested significant in any of the alternative specifications. 
The North American (domestic) content for the two models of BMWs assembled at the South Carolina plant is only 35 percent. Major parts like engines and transmissions are all European imports. According to figures provided by BMW, the content supplied by firms from South Carolina is only 37.4 percent of domestic purchases, making the South Carolina contribution 13.9 percent of the total value (37.4 percent times 35 percent). Even this figure may overstate the South Carolina contribution, since supplies that pass through supplier warehouses in South Carolina would be included as state-level purchases even if the item is manufactured outside the state and merely packaged or assembled in South Carolina. These facts, along with the regression results, fail to support the conclusions of the Economic Impact Analysis of the BMW Project for South Carolina (South Carolina State Development Board 1992).

The assumption that 21 new supplier chain firms would accompany the BMW plant opening and that these 21 new firms would contribute 2,793 new direct jobs to be used in estimating the total impact on the state economy is without merit. Additionally, the high $\mathrm{R}^{2}$ values for both models (over .92) suggest that the models themselves have good explanatory power in identifying the average annual change in the number of firms per SIC industry over the 1982-1997 period.

Since the Mercedes-Benz plant in Alabama opened in 1997 and our data set ended in 1997, a similar set of regressions could not be completed given so few observations since the plant opened. If the results for the estimated impact of the BMW plant on the number of new South Carolina firms can be generalized to Alabama, it is likely that the 1,500 on-site jobs did not generate the assumed 2,875 net new direct supplier chain jobs used in the Alabama impact study. There is no obvious reason to expect that the smaller Alabama plant will have a larger influence on the state economy than the BMW plant has had on the South Carolina economy.

\section{CONCLUSIONS}

This paper investigated the appropriateness of the methodologies employed in the economic impact studies done for the BMW assembly plant in South Carolina and the Mercedes-Benz assembly plant in Alabama. These impact studies for South Carolina (BMW) and Alabama (Mercedes-Benz) were used, in part, to justify large economic incentive offers derived from taxpayer revenues. The focus of this investigation was on the contention in each of these studies that a large number of supplier chain jobs and firms would be created by the location decision, and that these jobs would represent new direct jobs to the state. InputOutput derived employment multipliers were then applied to the combined total of project on-site direct jobs and supplier chain direct jobs to estimate indirect/induced job impact.

The methodology used in both of these studies produced effective on-site job multipliers more than double the SIC 371 RIMS II job multipliers for each respective state. Additionally, these effective multipliers approach or exceed the SIC 371 RIMS II employment multipliers in Michigan, Ohio, and the other eight states with the highest levels of SIC 371 employment. 
The assumption that anticipated supplier chain jobs should be treated as additional direct jobs leads to what appear to be exaggerated employment impacts. This is likely because input-output employment multipliers already reflect a level of indirect supplier chain jobs based on the states' current economic structures. The existing state multipliers do not preclude the possibility that the additional indirect employment will come from new supplier chain firms. Thus, only net new supplier chain jobs that are over and above those already built into the current multipliers should be treated as new direct jobs that will generate additional induced /indirect jobs.

A second methodological mistake was made in both the South Carolina and Alabama studies. In both studies, the multiplier for SIC code 371 was applied to the estimated new supplier chain jobs that were identified as direct jobs. A more appropriate estimating approach would be to project the net increase in the number of new supplier chain firm jobs, and apply each supplier chain firm's unique RIMS II SIC code multiplier to estimate the indirect/induced and total job impacts on the South Carolina or Alabama economy on an industry by industry basis.

Our results fail to support the assumption made in the South Carolina impact study that 21 net new supplier chain firms would accompany the BMW plant opening and that these 21 new firms would contribute 2,793 new direct jobs. The results in both Table 5 and Table 6 fail to show any impact of the BMW plant on the number of firms in the 34 manufacturing supplier chain industries. The limited amount of South Carolina-produced supplier content further strengthens the argument that what are normal indirect supplier chain jobs should not be treated as new direct jobs.

The results of this study appear to be consistent with the findings of both Reid (1995) and Klier (1999). Reid's (1995) results showed that there is only a significant local concentration of supplier chain plants around Japanese assembly plants that use JIT inventory control systems. Klier's (1999) results support the argument that supplier chain firms have tended to remain in the upper Midwest to take advantage of the well-established infrastructure and the ability to serve multiple assembly plants. In addition, the results of this paper are in line with the notion that the economic development environment has evolved into an "arms race" (Jenn and Nourzad 1996), which encourages optimistic economic impact estimates to justify larger and larger state-sponsored relocation incentives.

Additional research is necessary to fully investigate the questions raised in this study. The actual employment impacts in South Carolina may be addressed if the state were to make the nondisclosed employment data available. Given sufficient time, enough data will be available to apply the same analysis to the impact of the Mercedes-Benz plant in Alabama. Accurate economic impact studies should be an objective of all concerned with the cost-effective use of taxpayer incentives in industrial recruiting. At this point, it does appear that the methodologies used in the South Carolina BMW and Alabama Mercedes-Benz economic impact studies contained an assumption that resulted in overstating the economic impact of the respective plants. 


\section{APPENDIX}

SIC Manufacturing Supplier Chain Industries for SIC 3711: Motor Vehicles and Car Bodies

\begin{tabular}{llll}
\hline SIC Code & Material & SIC Code & Material \\
\hline 371401 & Gas Engines and parts & 331085 & All other steel shapes \\
351902 & Diesel Engines and parts & 336002 & Nonferrous shapes \\
371463 & Transmissions and parts & 356200 & Ball and roller bearings \\
371462 & Axles and axle parts & 301101 & Pneum. Tires and tubes \\
371471 & Wheels, motor vehicle & 305201 & Rubber and plas.hose \\
371481 & Brake parts and assemblies & 306902 & Fabr. Rubber prod. \\
371464 & Other drive train components & 305302 & Gaskets, packing \\
371110 & Car bodies & 308025 & Fabr. Plastic prod. \\
358501 & Heat transfer equipm. & 320102 & Glass, glass prod. \\
371402 & Shocks, struts, susp. & 253121 & Seats \\
371451 & Exhaust systems & 239901 & Seat covers \\
354500 & Machine tool acces. Cutting & 371491 & Autom. Airbag \\
359412 & Pumps and hydrost. Transm. & 239621 & Autom. Trimmings, textile \\
349271 & Valves & 227002 & Carpeting \\
359301 & Cylinders, rot. Actuators & 320601 & Ceramic and cer. Prod. \\
349261 & Hose or tube fittings & 289101 & Glues and adhesives \\
356921 & Filters & 285101 & Paints, varnishes \\
190089 & Other fluid power prod. & 369401 & Engine electric. Equipm. \\
346501 & Autom. Stampings & 364701 & lighting fixtures \\
349301 & Steel springs & 364102 & Autom. Lamps \\
342961 & Met. Hardware & 369104 & Storage batteries \\
345001 & Bolts, nuts, screws & 365101 & Autom. Radio and Speakers \\
340071 & Other fabric. Met. Pro. & 382441 & Vehicle clusters, meters, gaug. \\
346000 & Forgings & 970099 & All other materials and comp. \\
330091 & Castings & 971000 & Mat. Ingredients, containers \\
331022 & Sheet and strip & & \\
\hline
\end{tabular}

\section{REFERENCES}

Homles, Mac R., and Ed McCallum. Economic Impact Analysis of the Mercedes-Benz A.G. Multipurpose Vehicles Production Facility for the State of Alabama. Troy, Ala.: Troy State University and Flour Daniels Siting and Consulting Services, 1993.

Jenn, Mark A., and Farrokh Nourzad. "Determinants of Economic Development Incentives Offered by States: A Test of the Arms Race Hypothesis." The Review of Regional Studies 26 (1996), 1-16.

Klier, Thomas H. "Spatial Concentration in the U.S. Auto Supplier Industry." The Review of Regional Studies 29 (1999), 294-305

Reid, Neil. "Just-in-Time Inventory Control and the Economic Integration of Japanese-Owned Manufacturing Plants with the County, State, and National Economies of the United States." Regional Studies 29 (1995), 345-356.

South Carolina State Development Board. Economic Impact Analysis of the BMW Project for South Carolina. Columbia, S.C.: Division of Research and Communications, June 1992.

U.S. Department of Commerce. Regional Multipliers: A Users Handbook for the Regional Input-Output Modeling System (RIMS II). Washington, D.C., May 1992. 
